\title{
O Processo de emancipação das mulheres a partir das teorias de Simone de BEAUVOIR: UM ENFOQUE FEMINISTA DO CONCEITO DE TRANSCENDÊNCIA
}

\author{
Tom Menezes Pedrosa*
}

\begin{abstract}
RESUMO
Este artigo pretende explorar a questão da autoafirmação da subjetividade das mulheres por meio da transcendência, conceito central na obra $O$ Segundo Sexo, de Simone de Beauvoir. Neste sentido, far-se-á um minucioso estudo da utilização do conceito de transcendência, sob a ótica existencialista, porém seguindo o enfoque feminista dado por Beauvoir, a fim de reconstruir a condição de opressão da mulher e os meios de superá-la. Dar-se-á ênfase não apenas às questões da má-fé e da cumplicidade, como também da situação, que é ponderada por Beauvoir. Serão identificados e esmiuçados, ainda, aspectos importantes das teorias da autora sobre o conceito em tela: a importância de uma ação feminina em conjunto, além da fraternidade entre homem e mulher, a fim de que os projetos de um possam incorporar os projetos do outro.

Palavras-chave: Transcendência; Liberdade; Existencialismo; Beauvoir; Feminismo.
\end{abstract}

* Graduado em Direito; Mestrando em Filosofia (UFABC).

Revista Páginas de Filosofia, v. 9, n. 2, p. 183-200, jul.-dez. 2020 


\title{
THE PROCESS OF WOMEN'S EMANCIPATION BASED ON SIMONE DE BEAUVOIR'S THEORIES: A FEMINIST APPROACH TO THE CONCEPT OF TRANSCENDENCE
}

\begin{abstract}
This article intends to explore the issue of self-affirmation of subjectivity of women through transcendence, a concept central to the work The Second Sex, by Simone de Beauvoir. In this In this sense, a detailed study will be made of the use of the concept of transcendence, under the existentialist perspective, but following the feminist approach given by Beauvoir, in order to reconstruct the condition of oppression of women and the means to overcome it. To give-emphasis will be placed not only on issues of bad faith and complicity, as well as the situation, which is considered by Beauvoir. Will be important aspects of the author's theories about the concept on female action together, in addition to fraternity between men and women, so that the projects of one can incorporate the other's projects
\end{abstract}

Key-words: Transcendence; Freedom; Existentialism; Beauvoir; Feminism.

\section{INTRODUÇÃo}

Ao longo de $O$ Segundo Sexo, a filósofa existencialista, Simone de Beauvoir, relata que a desigualdade entre homens e mulheres ocorre devido a obstáculos estruturais e a normas poderosas que prejudicam as mulheres em seu objetivo de transcender. Desta forma, pode-se inferir que a transcendência das mulheres não é efetivada em razão de o poder estrutural configurado até então apresentá-las como subordinadas e inferiores aos homens. Isso se dá de tal forma que a transcendência, mesmo que ontológica, não possa ser concretizada pela simples força de vontade.

Beauvoir, contudo, mantém-se fiel ao conceito de transcendência como o destino dos seres humanos. No início de $O$ Segundo Sexo, há uma trajetória de aprimoramento constante integrada ao relato histórico de Beauvoir. Mas não há um único lugar da obra em que se explica o porquê de a posição econômica, política e social das mulheres melhorar. Em vez disso, é como se Beauvoir esperasse que seus leitores acreditassem que uma lenta luta política trouxesse uma lenta, mas contínua liberdade para as mulheres. 
Neste sentido, a combinação de demandas das mulheres, como por exemplo: por maior igualdade de direitos e maior independência econômica; por um controle sobre a reprodução biológica ${ }^{1}$, que dá à mulher mais opções nos papéis que ela assume na família e no trabalho; por uma maior consciência das mulheres sobre o papel que a feminilidade desempenha em seu status de segunda classe, tudo isso trabalha - em conjunto - a fim de avançar rumo ao tão disputado progresso.

Por isso, Beauvoir compreende que há ganhos árduos e demorados os quais as mulheres conquistam em sua luta pela liberdade. A filósofa apega-se, então, à ideia de transcendência como parte integrante do ser humano. Mas o que exatamente se entende por transcendência? 0 presente artigo tentará responder a essa questão com base nas teorias de Beauvoir, constantes na obra "O Segundo Sexo".

\section{A INCAPACIDADE FEMININA EM DIZER "NóS"}

É inerente à mulher ${ }^{2}$, como a todo ser humano, sua condição de projeto e, através dele, adquirir a potência de realizar sua liberdade,

1 “Além disso, embora Beauvoir insista que a biologia não é um 'destino', as construções sociais - inscritas no corpo feminino - são centrais na definição da mulher não apenas como outro, mas como um outro inferior." (KRUKS, 1995, p. 85, tradução nossa). ["Furthermore, although Beauvoir insists that biology is not a "destiny", the social constructions placed on the female body are very central in defining woman not only as other but as inferior other"].

2 Destaca-se que, por assinar uma obra engendrada a partir de epistemologias brancas e eurocêntricas, Simone de Beauvoir sofre críticas de teóricas do feminismo da diferença, no que se refere à questão da interseccionalidade, a qual rejeita uma categorização abstrata de mulher universal. "Segundo Butler, a construção de uma categoria mulheres como um sujeito estável, coerente e universal implica interpretações problemáticas e obscurece as diferenças no interior dessa categoria" (FEMENÍAS, María Luisa. A crítica de Judith Butler a Simone de Beauvoir. In: Sapere Aude, v. 3, n. 6, 2012, p. 332). No entanto, é necessário frisar que Beauvoir não aparentava estar completamente alheia ao tema. Isso parece evidente quando enuncia que "burguesas são solidárias dos burgueses e não das mulheres proletárias; brancas, dos homens brancos e não das mulheres negras" (BEAUVOIR, Simone de. O segundo sexo: fatos e mitos; tradução Sérgio Milliet. - 3. ed. - Rio de Janeiro: Nova Fronteira, 2016, p. 16). Tendo em vista que muitas destas pautas ainda não faziam parte da agenda feminista, na época em que $O$ Segundo Sexo foi escrito, pode-se dizer que Beauvoir teve um insight precursor e, decerto, sua teoria foi indispensável para que se chegasse ao feminismo interseccional. 
revelando-se um sujeito livre e transcendente sem embargo de sua situação única: isso somente será possível se a mulher não boicotar suas possibilidades de transcendência, caindo em má-fé3.

Essa iniciativa tem, igualmente, um dado social, já que o apoderamento da liberdade requer a ampliação da liberdade dos outros: "nenhum projeto se define senão por sua interferência com outros projetos. Fazer com 'que haja ser' é comunicar através do ser com o outro. (...) Querer-se livre é também querer livres os outros” (BEAUVOIR, 1970, pp. 59-61). Precisa haver, portanto, uma mudança de paradigma, com a desestruturação dos sustentáculos do modelo patriarcal, e tal conduta não deve ocorrer de maneira individual, como ressalta o filósofo australiano, Jack Reynolds:

Tanto em O Segundo Sexo como em Por uma moral da ambiguidade, de Beauvoir, por outro lado, argumenta que a transcendência de um indivíduo (ou liberdade) na verdade requer a liberdade e a transcendência de outras pessoas. Ela sugere muito claramente que "não é verdade que o reconhecimento da liberdade de outros limite minha própria liberdade: ser livre não é ter o poder de fazer qualquer coisa que quisermos; é sermos capazes de ultrapassar o dado em direção a um futuro aberto" (EA: 91). E ela sugere que é outra pessoa que pode ajudar-nos a criar um futuro aberto. Vimos como isso se dá em relação a pessoas oprimidas necessitando ser capazes de conceber um projeto comum, mas também podemos pensar sobre o ponto de Simone de Beauvoir de um modo que seja relevante para todos nós, sejamos nós oprimidos ou não. Descobertas, invenções, indústrias, cultura, pintura e livros são todos exemplos de transcendência pelas pessoas individuais. Contudo, essas ideias e descobertas também abrem novas possibilidades concretas para outras pessoas e novas oportunidades para a transcendência. (REYNOLDS, 2014, p. 213)

Beauvoir alega, ademais, que às mulheres faltaram-lhe, ao longo da história, coesão. Sempre estiveram espalhadas entre os homens e ligadas a eles "pelo habitat, pelo trabalho, pelos interesses econômicos, pela condição social (...) mais estritamente do que a outras mulheres" (BEAUVOIR, 2016a, p. 16). Em outros termos, Beauvoir compreende que:

\footnotetext{
Apesar de Beauvoir considerar "que Sartre exagere no uso que faz de seu conceito de má-fé, ela o incorpora, só que em cores mais suaves” (CYFER, 2015, p. 69), já que o problema da situação será sempre ponderado.
} 
Uma mulher branca rica, mesmo que seja oprimida e relegada a um papel servil, sentir-se-á mais ligada a homens brancos ricos, por exemplo, do que a mulheres pobres (SS: 19). O ponto de Simone de Beauvoir é simplesmente que a identidade feminina, devido aos modos pelos quais a sociedade foi organizada, é muito vinculada à identidade dos homens ao redor delas, sejam eles pais, maridos ou filhos. (REYNOLDS, 2014, p. 210)

Essa incapacidade feminina em dizer "nós"4 cria obstáculos às possibilidades de transcendência das mulheres, tornando-as inaptas a criar uma revolução, como o fizeram o proletariado, por exemplo, porquanto os interesses das mulheres nem sempre são os mesmos, devido à singularidade da situação de cada uma. Segundo Beauvoir (2016a, p. 16), "o laço que a une a seus opressores não é comparável a nenhum outro. (...) Isso é o que caracteriza fundamentalmente a mulher: ela é o Outro dentro de uma totalidade cujos dois termos são necessários um ao outro."

\section{A ESCOLHA ENTRE O CAMinho Da liberdade}

E O CAMINHO DA CUMPLICIDADE

Às mulheres, Beauvoir refere-se - em Moral da ambiguidade - com parcimônia e, quando o faz, compara as mulheres aos escravos, como "seres cuja vida inteira decorre num mundo infantil, porque, mantidos num estado de servidão e ignorância, não possuem nenhum meio de quebrar esse teto estendido sobre suas cabeças" (BEAUVOIR, 1970, p. 31).

Na sequência, Beauvoir afirma, ademais, que aquilo que diferencia as mulheres de uma verdadeira criança é que "à criança, sua situação é

4 "Kruks argumenta que a transição da opressão para a transcendência livre pode se dar somente quando 'minha' situação não é, estritamente falando, minha, mas também parte de uma situação mais geral que transcende minhas experiências imediatas. Kruks, por conseguinte, reafirma a importância da conscientização de uma coletividade, de um 'nós', para qualquer processo emancipatório, e é isso que de Beauvoir argumenta que as mulheres, de um modo geral, não têm tido. A afirmação de 'irmandade' no feminismo dos anos de 1970 foi uma tentativa de mudar essa situação e habilitar as mulheres a se conceberem como unidas umas às outras. Afinal, uma mulher individual pode discordar de uma situação social patriarcal, mas sua liberdade pessoal não resultará em uma ação sem outras sentindo-se de modo similar. Para seu desacordo com aspectos particulares de suas vidas fermentar e se tornar uma revolução, é necessário que as pessoas ao redor delas também sejam livres e transcendentes" (REYNOLDS, 2014, p. 210-211).

Revista Páginas de Filosofia, v. 9, n. 2, p. 183-200, jul.-dez. 2020 
imposta, enquanto que a mulher (penso na mulher ocidental) a escolhe ou pelo menos concorda com ela" (BEAUVOIR, 1970, p. 32). Esse é o único momento em que, nesse texto, Beauvoir aborda a questão feminina.

No entanto, essa perspectiva retorna, anos depois, em um debate similar, em $O$ Segundo Sexo, no qual Beauvoir afirma que a mulher "muitas vezes, se compraz no seu papel de Outro" (BEAUVOIR, 2016a, p. 18). Em função disso, há uma tensão latente em $O$ Segundo Sexo, até a última página, a fim de buscar respostas sobre de que forma a mulher pode vir a reconhecer a possibilidade de transcender sua imanência e, à vista disso, como ela faz a escolha entre o caminho da liberdade e o caminho da cumplicidade, sendo este último "uma demissão da liberdade, demissão que implica má-fé e que é uma falta positiva" (BEAUVOIR, 1970, p. 32).

Por este ângulo, Beauvoir traz ao debate urgências concretas que são necessárias à emancipação da mulher e à recuperação de sua individualidade, pois "já é tempo, em seu interesse e no de todos, de deixá-la enfim correr todos os riscos, tentar a sorte" (BEAUVOIR, 2016b, p. 540). Sendo assim, Beauvoir propõe que as mulheres transcendam por meio de livres projetos próprios, aceitando todas as incertezas, riscos e perigos que isso implica. Como tal, "a mulher 'moderna' aceita os valores masculinos: tem a pretensão de pensar, agir, trabalhar, criar da mesma maneira que os homens; em vez de procurar diminuí-los, afirma que se iguala a eles" (BEAUVOIR, 2016b, p. 543).

\subsection{A transubstanciação de valores tradicionalmente masculinos}

Para garantir a igualdade das mulheres, Beauvoir pleiteia alterações substantivas nas estruturas sociais, como educação igualitária, contracepção e aborto legal, assistência universal à infância, e talvez o mais importante: liberdade econômica e independência financeira em relação aos homens. Para alcançar esse tipo de independência, Beauvoir acredita que as mulheres beneficiar-se-ão, até certo ponto, do trabalho não-alienante, produtivo e sem exploração; isto é, Beauvoir acredita que as mulheres poderão tirar enorme proveito da atividade laboral.

Contudo, para ela, no que diz respeito ao casamento, a família nuclear é prejudicial para ambos os parceiros, especialmente para a 
mulher: o casamento, como qualquer outra eleição autêntica, deve ser escolhido ativamente e em todos os momentos; quando não, passa a ser uma fuga da liberdade em uma instituição estática.

É fácil imaginar um mundo em que homens e mulheres seriam iguais, porquanto é exatamente o que prometera a revolução soviética: as mulheres, educadas e formadas exatamente como os homens, trabalhariam em condições idênticas e por salários idênticos; a liberdade erótica seria admitida pelos costumes, mas o ato sexual não seria mais considerado um "serviço" que se remunera; a mulher seria obrigada a assegurar-se outro ganha-pão; o casamento repousaria em um compromisso livremente assumido e que os cônjuges poderiam anular quando o quisessem; a maternidade seria livre, isto é, autorizariam o controle de natalidade e o aborto, e em compensação dariam a todas as mães e a seus filhos exatamente os mesmos direitos, fossem ou não casadas; as licenças por gravidez seriam pagas pela coletividade que assumiria o cuidado dos filhos, o que não quer dizer que estes seriam retirados dos pais e sim que não lhes seriam abandonados. (BEAUVOIR, 2016b, p. 549-550)

Para Reynolds ${ }^{5}$, algumas filósofas como Michèle Le Doeuff $(A$ escolha de Hipárquia) e Genevieve Lloyd (Homem de razão) defendem, de modo diverso, que essa abordagem existencialista de Beauvoir é deficiente e não favorece o feminismo, devido à importância dada à atividade e à transcendência. Para elas, é preciso transgredir tais conceitos beauvoirianos, por serem calcados em gênero e, por conseguinte, subtenderem comportamentos sociais e modos de vida que - tacitamente limitam as mulheres ao ambiente doméstico. Le Doeuff e Lloyd afirmam, ainda, que Beauvoir apropria-se de valores tradicionalmente masculinos a fim de transubstanciá-los em objetivos para as mulheres. Isto é:

Beauvoir às vezes parece assumir que certos tipos de projetos no mundo são o tipo mais valioso de atividade, sem pensar que talvez essa seja uma concepção masculina de valor que necessita ser colocada em questão. E não pode ser negado que de Beauvoir está particularmente interessada na vida pública, seja escrevendo filosofia ou livros de literatura, seja liderando negócios ou partidos políticos. Ela sugere tacitamente

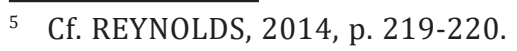

Revista Páginas de Filosofia, v. 9, n. 2, p. 183-200, jul.-dez. 2020 
que esses são os tipos de projetos que as mulheres deveriam objetivar, uma vez que são os mais transcendentes, e (...) existe também em seu trabalho uma consequente desvalorização da gravidez, da maternidade, da administração do lar, e assim por diante. (REYNOLDS, 2014, p. 220)

Isso porque, de acordo com algumas interpretações, o corpo feminino é abordado por Beauvoir "como algo sujo e indesejado, que aprisiona a mulher em suas funções biológicas, o que (...) implicaria abraçar o determinismo biológico que a mais célebre frase do livro, 'não se nasce mulher, torna-se mulher'6, parece desmentir" (CYFER, 2015, p. 61). Infere-se de tal frase, aliás, que a proposta de Beauvoir passa pela premissa de que é fundamental para um indivíduo pensar em si mesmo como um ser humano, em vez de se definir como um ser sexuado e assumir papéis de acordo com seu sexo.

6 Faz-se pertinente citar trecho do voto do Ministro do Supremo Tribunal Federal, Celso de Mello, a fim de dar seguimento ao julgamento da Ação Direta de Inconstitucionalidade por Omissão (ADO) 26, que, quando em trâmite, apontava omissão do Congresso Nacional em não editar lei que criminalizasse atos de homofobia e transfobia: "Essa visão de mundo, Senhores Ministros, fundada na ideia, artificialmente construída, de que as diferenças biológicas entre o homem e a mulher devem determinar os seus papéis sociais ("meninos vestem azul e meninas vestem rosa"), impõe, notadamente em face dos integrantes da comunidade LGBT, uma inaceitável restrição às suas liberdades fundamentais, submetendo tais pessoas a um padrão existencial heteronormativo, incompatível com a diversidade e o pluralismo que caracterizam uma sociedade democrática, impondo-lhes, ainda, a observância de valores que, além de conflitarem com sua própria vocação afetiva, conduzem à frustração de seus projetos pessoais de vida. É por isso que SIMONE DE BEAUVOIR, em sua conhecida obra "O Segundo Sexo" ("Le Deuxième Sexe", tomo I, "Les Faits et Les Mythes" e, tomo II, "L'expérience Vécue”, Ed. Gallimard), escrita em 1949, já manifestava a sua percepção em torno da realidade de que sexo e gênero constituem expressões conceituais dotadas de significado e de sentido próprios, sintetizando, em uma fórmula tipicamente existencialista e fenomenológica, de caráter tendencialmente feminista (op. cit., vol. 2/11, 3 a ed., 2016, Ed. Nova Fronteira), que "On ne naît pas femme: on le devient" ("Ninguém nasce mulher: torna-se mulher"). Isso significa, portanto, como já se escreveu, que a liberdade e a autenticidade de cada ser humano constituem valores revestidos de inquestionável essencialidade, a revelar que o indivíduo, sendo fautor de seu próprio destino, deve conduzir a sua vida segundo suas escolhas fundadas em valores por ele aceitos e aos quais ele voluntariamente se submete no exercício de sua liberdade pessoal e na prática efetiva de sua capacidade de autodeterminação." (STF, 2019, on-line).

Revista Páginas de Filosofia, v. 9, n. 2, p. 183-200, jul.-dez. 2020 


\subsection{A mulher como um cruzamento entre liberdade e reificação}

A mulher foi adestrada a pensar em si mesma a partir do seu sexo; o homem, em contrapartida, "não começa nunca por se apresentar como um indivíduo de determinado sexo: que seja homem é evidente" (BEAUVOIR, 2016a, p. 11), dado que o gênero masculino simboliza o tipo humano absoluto. Por isso, em sua biografia, a filósofa afirma:

Um dos mal-entendidos que meu livro suscitou foi que se pensou que nele eu negava qualquer diferença entre homens e mulheres: ao contrário, ao escrevê-lo, medi o que os separa; o que sustentei foi que essas dessemelhanças são de ordem cultural, e não natural. Contei sistematicamente como elas se criam, da infância à velhice; examinei as possibilidades que este mundo oferece às mulheres, as que lhes são recusadas, seus limites, suas oportunidades e faltas de oportunidades, suas evasões, suas realizações. (BEAUVOIR, 1995, p. 168 e 169)

Beauvoir, destarte, não planeja a desaparição total das diferenças de gênero; longe disso: essas diferenças devem existir em igualdade. A falha está em compreender as diferenças relativamente à subordinação e à opressão e, a partir disso, estabelecer uma essência feminina. Só é possível descontruir essa feminilidade ${ }^{7}$ normativa se for rompida a estrutura da alteridade que transforma a mulher na figura do Outro sem reciprocidade, isto é, "o que está em questão não é apenas a alteridade, mas a subordinação, a reificação que não é recíproca" (CYFER, 2015, p. 67).

De acordo com a filósofa Wanda Tommasi ${ }^{8}$, a obra de Beauvoir localiza-se, outrossim, na dimensão feminista da igualdade, definindo as

70 agrupamento de regras imposto ao feminino, com o propósito de circunscrever o ser mulher, chama-se "feminilidade", a qual carrega a ideia de que há coisas que são próprias de mulher, enquanto outras não. "Todo ser humano do sexo feminino não é, portanto, necessariamente mulher; cumpre-lhe participar dessa realidade misteriosa e ameaçada que é a feminilidade. Será esta secretada pelos ovários? Ou estará congelada no fundo de um céu platônico? E bastará uma saia fru-fru para fazê-la descer à Terra?" (BEAUVOIR. Op. Cit., pp. 9-10).

8 Cf. TOMMASI, 2002, p. 188.

Revista Páginas de Filosofia, v. 9, n. 2, p. 183-200, jul.-dez. 2020 
mulheres como uma construção sociocultural que é resultado da educação. Não há, pois, uma diferença que deve ser afirmada como um valor, como é o caso do feminismo da diferença. Logo, não há especificidade feminina para valorizar, há apenas uma desigualdade a ser superada em relação aos homens, uma imanência que se deve tornar transcendência.

A imanência, a propósito, implica uma essência feminina que equivale a um ideal daquilo que a mulher deveria ser. Ao louvar-se as concepções patriarcais do corpo feminino (a maternidade, por exemplo), e tentando-se definir a subjetividade feminina baseada nesses padrões, promove-se a ratificação do sistema patriarcal, posto que este sintetiza as mulheres em figuras frágeis, passivas e submissas. A transcendência, de outro modo, exige que as mulheres apropriem-se de sua existência e coloquem-se como iguais perante os homens, isto é, como seres humanos capazes de escolher seu sexo, suas vocações ou seu ofício.

Desta forma, a emancipação feminina não consegue se desenvolver num universo patriarcal em que as condições econômicas, morais e psíquicas lançam a mulher de volta à sua imanência. Deve, ao contrário, desenvolver-se num mundo em que mulheres e homens reconheçam um ao outro como sujeitos livres e transcendentes; em outras palavras, homens e mulheres devem identificar-se com projetos autênticos, através dos quais cada um assume a responsabilidade de suas escolhas ao agir e, por conseguinte, conduz essas ações de modo transcendente ao mundo e aos outros.

Isso é o que é preciso para, nos termos de Beauvoir, assumir a responsabilidade de construir o mundo em coautoria. Ser coautora é, portanto, diferente de ser sujeito ou objeto absoluto. É habitar ambas as condições simultaneamente, assumindo-se como um cruzamento entre liberdade e reificação. Essa é, enfim, a cena do reconhecimento em que Beauvoir situa a relação igualitária entre homens e mulheres. (CYFER, 2015, p. 72)

Posto isso, a situação tem um papel crucial, na filosofia existencial de Beauvoir, para a concretização da liberdade. Desta forma, a liberdade feminina precisa ser compreendida segundo a conjuntura de uma situação particular: se as mulheres não são sujeitos livres, 
isso se deve - parcialmente - à má-fé, que reflete sua opressão, mas sobretudo - à facticidade de sua situação, já que o contexto histórico, socioeconômico e político oprime-as de forma transversal. Isto é, caso não haja um futuro aberto, a capacidade de transcendência é sufocada e limitada; por consequência, apenas a igualdade social possibilitará a transcendência recíproca. ${ }^{9}$

\section{LIBERDADE E TRANSCENDÊNCIA}

Não se pode ignorar que Beauvoir indica uma relação inevitável entre as noções de liberdade e de transcendência, a fim de adotar um projeto ético calcado na concepção de que os propósitos de um sujeito necessitam de outros sujeitos para que se realizem.

Logo, a comunhão entre as ideias de transcendência e de liberdade põe em relevo o entendimento de que, mesmo que a mulher possua a consciência de que pode assumir-se livre e transcendente no intuito de pôr em prática sua liberdade, faz-se necessária uma comunidade que dê suporte e participe da efetivação de seus projetos. Em outras palavras, a mulher precisa de um ambiente e de um contexto social que possibilite tal realização.

Por esse motivo, o mundo no qual está inserida a mulher não pode ser aquele em que o princípio masculino seja o parâmetro para tudo aquilo que é humano; caso contrário, há uma polarização das atividades femininas, de modo essencialista e sexista, perante as atividades masculinas. Não é o bastante, destarte, a simples tomada de consciência individual das mulheres sobre sua situação, sendo indispensável uma mudança de paradigmas na sociedade como um todo.

Ao analisar as teorias de Beauvoir a partir de Pirro e Cinéias, uma de suas obras, a filósofa estadunidense Debra Bergoffen ${ }^{10}$ afirma que os projetos individuais precisam englobar os projetos dos outros. $\mathrm{Na}$ medida em que, subitamente, cada indivíduo, em sua existência, deve encarar a alteridade dos outros, é impossível menosprezar-lhes a existência; deve-se, então, haver uma ação em conjunto.

\footnotetext{
9 Cf. REYNOLDS, 2014, p. 215.

10 Cf. WEISS, 2006, pp. 249-250.
}

Revista Páginas de Filosofia, v. 9, n. 2, p. 183-200, jul.-dez. 2020 
De fato, Beauvoir não tem esperança na capacidade de uma mulher individualmente vencer a opressão feminina. (...) A "mulher independente", que retrata no último capítulo do livro, não é produto de um projeto individual, e sim do conjunto de instituições e práticas culturais do mundo em que vive. (...) Por isso, para Beauvoir, a luta contra a opressão feminina pressupõe mudanças nas leis, instituições, costumes, opinião pública, nas condições econômicas e profissionais das mulheres. E essas mudanças não podem ser alcançadas individualmente. (...) Beauvoir exorta as mulheres à ação coletiva, uma luta que emancipará não apenas as mulheres, mas também os homens. Isso porque, na dialética de Beauvoir, a luta contra a opressão é a luta pelo reconhecimento mútuo. (CYFER, 2015, pp. 70-71)

Por esse motivo, é possível dizer que, segundo o pensamento de Beauvoir, a mulher oprimida não é a única responsável por sua opressão, ou seja, não basta que ela sofra uma transformação individual para mudar sua situação e libertar-se; em vez disso, a transformação deve acontecer no universo masculino em que se encontra a mulher para que ela seja capaz de projetar ações livres e, assim, transcender.

\subsection{A complexidade da condição feminina: fatores econômicos e psicossociais}

Cabe refletir de que forma, sob a perspectiva beauvoiriana, dar-se-ia o mundo no qual a mulher pudesse exercer seu poder de transcendência e gozar plenamente da sua condição de sujeito livre. $\mathrm{E}$, diante de todo esse enredamento, convém repensar como aclarar a possibilidade de a mulher transcender seus atos para fins específicos e realizar sua liberdade prática, a partir do seu "nada" e a despeito de sua situação.

Afirma Beauvoir (2016b, p. 503), em O Segundo Sexo, que "só o trabalho pode assegurar-lhe uma liberdade concreta. Desde que ela deixa de ser um parasita, o sistema baseado em sua dependência desmorona; entre o universo e ela não há mais a necessidade de um mediador masculino". Neste capítulo, intitulado A mulher independente, a filósofa pondera que o trabalho, conquanto traga retorno financeiro à mulher, não é o bastante para transmutar substancialmente a situação feminina: "a mulher que se liberta economicamente do homem nem por 
isso alcança uma situação moral, social e psicológica idêntica à dele"11 (BEAUVOIR, 2016b, p. 505).

Sendo assim, a complexidade da condição feminina está cercada por ordenações socioeconômicas concretas que, por seu turno, têm encadeamentos psicológicos no processo de construção da individualidade da mulher, mantendo-a subordinada à atividade masculina. Não é simples, portanto, obliterar o "adestramento" a que foi submetida, desde a tenra infância, a fim de "tornar-se mulher".

Neste seguimento, é plausível, para Beauvoir, que a mulher, mesmo estando num universo masculino, atinja sua liberdade. Para tal fim, deve o sujeito evitar aludir à sua situação, como se esta fosse incondicionalmente decisiva. A mulher precisa, ao contrário, estar consciente de sua condição como projeto guarnecido de intencionalidade. Isso irá norteá-la a fim de combater sua angústia existencial, além de poupá-la da denegação de sua facticidade, caindo em má-fé.

\subsection{A liberdade como condição humana}

A mulher abraça a responsabilidade e as consequências de uma intervenção concreta no mundo. Isto é, não apenas ela - a mulher deve assumir sua condição de sujeito livre, como também a sociedade deverá fazê-lo, porquanto, a liberdade é - de acordo com Beauvoir - uma condição humana; logo, a humanidade das mulheres deverá, primeiro, ser reconhecida para que elas possam tornar-se sujeitos livres e transcendentes.

Por esse motivo, aquilo que é humano ${ }^{12}$ não poderá ter como diretriz apenas o que se constitui como masculino: os dois sexos pre-

11 "Por certo não se deve crer que baste modificar-lhe a situação econômica para que a mulher se transforme: esse fator foi e permanece o fator primordial de sua evolução; mas enquanto não tiver acarretado as consequências morais, sociais, culturais etc. que anuncia e exige, a nova mulher não poderá surgir" (BEAUVOIR, 2016b, pp. 550-551).

12 Vale ressaltar, a propósito, que, apesar de - em suas primeiras obras filosóficas Beauvoir fazer menção ao ser humano (lato sensu), a autora deixa, em $O$ Segundo Sexo, de versar sobre o homem (ou humano) universal para analisar a mulher e sua singular situação. Doravante, a filósofa francesa inicia uma desconstrução do modelo universal de ser humano e parte para exames mais rigorosos sobre a questão feminina, pois percebe e denuncia a dificuldade em se analisar a condição peculiar das mulheres a partir de um ser humano universal.

Revista Páginas de Filosofia, v. 9, n. 2, p. 183-200, jul.-dez. 2020 
cisam reconhecer-se como iguais. Assim, para Beauvoir (2016b, pp. 556-557), é no momento em que "for abolida a escravidão de uma metade da humanidade e todo o sistema de hipocrisia que implica, que a 'divisão' da humanidade revelará sua significação autêntica e que o casal humano encontrará sua forma verdadeira." No atual contexto social, pode-se dizer que, em inúmeros aspectos, essa metade da humanidade ainda permanece presa à imanência.

Logo, ser sujeito ou ser humano diz respeito aos homens; de outra parte, o papel de outras - dentro desse humano genérico que é o homem - é exercido pelas mulheres: elas, privadas de sua posição de sujeitos, não existem, portanto, como fins em si mesmas, mas subordinadas aos homens.

Por isso, Beauvoir (2016b, p. 536) diz que as mulheres "não contestam a condição humana porque mal começam a poder assumi-la integralmente." Atribuir a si mesma a condição de sujeito livre e transcendente significa, para a mulher, opor-se ao ordenamento social pré-estabelecido, que a coisifica para a satisfação do patriarcado: a batalha feminina por libertação é profundamente insurgente. Através da avaliação desses aspectos, é possível perceber que a luta pela libertação da mulher consiste - para Beauvoir - na busca por sua afirmação como sujeito.

\section{A HUMANIDADE EM SUA DESSEMELHANÇA: RELAÇõES DE TROCA E FRATERNIDADE}

Diante disso, o caminho da libertação que buscam encontrar as mulheres contrasta com uma estrutura de sociedade paternalista cuja narrativa visa a reiterar, ao longo do tempo, a imanência feminina em oposição à transcendência masculina. Deste modo, a independência feminina é um objetivo que exige afã para ser alcançado: "se as dificuldades são mais evidentes na mulher independente é porque ela não escolheu a resignação e sim a luta" (BEAUVOIR, 2016b, p. 510).

Não se deve, ademais, restringir tal luta ao campo individual; ela deve, sim, demudar as condições materiais da mulher, mas também de todo o corpo social. E, conforme assegura Beauvoir, isso só pode se dar: 
graças a uma evolução coletiva. Nenhum educador isolado pode fabricar hoje um "ser humano fêmea" que seja o homólogo exato do "ser humano macho": educada como rapaz, a jovem sente-se excepcional e com isso sofre uma nova espécie de especificação. Stendhal bem o compreendeu quando dizia: 'é preciso plantar de uma só vez toda a floresta.' Mas se supormos, ao contrário, uma sociedade em que a igualdade dos sexos seja concretamente realizada, essa igualdade se afirmará como nova em cada indivíduo. (BEAUVOIR, 2016b, p. 551)

É por isso que, buscando - de forma individual - sua liberdade (e, portanto, ignorando a realidade de sua situação em meio a um universo masculino), a mulher incorrerá nas limitações imputadas pela especificidade de sua situação. No entanto, é viável a batalha feminina pela afirmação de si como sujeito livre; para tanto, a eficácia desse pleito torna indispensáveis dois pressupostos: a conquista individual da independência econômica; e um movimento de toda a coletividade em prol dessa luta por libertação (PARDINA, 1995, p. 173).

Todavia, o mundo ideal para que a mulher possa exercer, plenamente, seu poder de transcendência não necessita ser, por oposição, um mundo unicamente feminino; em vez disso, esse mundo só precisaria ser aquele em que toda a humanidade (princípios masculino e feminino abarcados) fosse capaz de ser compreendida em sua heterogeneidade, como atesta Beauvoir:

Em ambos os sexos representa-se o mesmo drama da carne e do espírito, da finitude e da transcendência; ambos são corroídos pelo tempo, vigiados pela morte, têm uma mesma necessidade essencial do outro; podem tirar de sua liberdade a mesma glória; se soubessem apreciá-la não seriam mais tentados a disputar-se privilégios falaciosos; e a fraternidade poderia então nascer entre ambos. (BEAUVOIR, 2016b, p. 554).

Na conclusão de $O$ Segundo Sexo, portanto, para que as crianças cresçam em equidade, um mundo andrógino ${ }^{13}$ é sugerido por Beauvoir; nele, as garotas esforçar-se-iam sem reticências em seus empreendimen-

13 Em tal mundo, "assumindo, da mesma maneira que o pai, a responsabilidade material e moral do casal, a mãe gozaria do mesmo prestígio duradouro." (BEAUVOIR, 2016b, p. 551).

Revista Páginas de Filosofia, v. 9, n. 2, p. 183-200, jul.-dez. 2020 
tos. ${ }^{14}$ Crianças de ambos os sexos desenvolver-se-iam, por consequência, cultivando respeito e admiração mútuos: a garota, então, sentir-se-ia reconhecida como sujeito. Numa sociedade assim engendrada, isto é, pautada no reconhecimento recíproco entre os sexos, relações de poder e subjugação dariam lugar a relações de troca e fraternidade.

\section{CONSIDERAÇões FINAIS}

Para a filosofia existencialista, o sujeito caracteriza-se por ser um projeto aberto à transcendência, ao contrário da imanência, que é patrimônio das coisas. Beauvoir, então, assume a tarefa de reconstruir a situação que instaura a condição feminina. Esta situação passa pela deslegitimação da ideia da existência de uma essência feminina, ao demonstrar como os homens impõem às mulheres que se assumam como consciência não essencial, ou seja, como o Outro.

A transcendência, todavia, define o ser humano a partir da ideia de que ele pode escolher livremente sua existência e seus projetos e, deste modo, assumir-se como verdadeiro ser humano. A humanidade consolida-se ao transcender, ou seja, ao poder escolher o que se quer ser ou fazer.

Uma existência isolada e solitária, no entanto, não é a liberdade que Beauvoir celebra e afirma em $O$ Segundo Sexo. Tendo isso em vista, os homens falham por subordinar conscientemente as mulheres, indo de encontro ao defendido por Beauvoir, desde Moral da Ambiguidade, isto é, eles tomam a direção contrária à ideia de liberdade como produtora da liberdade do outro. Essa subjugação coletiva não produz uma fraternidade.

Sabe-se, por esse ângulo, que ninguém está sozinho no mundo e que os atos de cada um criam uma nova situação à qual todos devem responder, forjando uma comunicação de uns com os outros, já que duas consciências só existem, uma para a outra, quando se relacionam entre si. Em suma, suspensa no vácuo, a humanidade só está livre para a ação transcendendo toda transcendência.

Outrossim, o termo Mitsein (ou ser-com), introduzido - na filosofia - pelo filósofo alemão Martin Heidegger, surge em $O$ Segundo Sexo

${ }_{14}$ Cf. BEAUVOIR, 2016b, pp. 551-552.

Revista Páginas de Filosofia, v. 9, n. 2, p. 183-200, jul.-dez. 2020 
no sentido de sermos indivíduos separados e dependermos de uma coletividade à qual pertencemos, sempre imediatamente em relação aos outros. Homens e mulheres sempre foram Mitsein, não dois grupos distintos e separados que apareceram e se confrontaram ao longo da história, como a burguesia e o proletariado. Beauvoir acrescenta que é fora deste Mitsein que a oposição entre homens e mulheres tomou forma (Cf. GOTHLIN, 2003, p. 45-65).

Portanto, uma ação é imoral quando suprime ou reprime as liberdades de outrem, ou seja, quando uma liberdade não se abre a outras liberdades, simplesmente as restringindo: isso é opressão. Logo, ao ser Sujeito livre e transcendente, uma consciência passa a habitar o corpo feminino, que deixa de ser mero corpo sexual e reprodutor. As rotas que levam à transcendência são, no entanto, sinuosas. Apesar da angústia que possa gerar ao percorrê-las, Beauvoir tenta, em seu livro, encorajar e orientar as mulheres a segui-las para que sejam capazes de exercer sua liberdade prática, através de projetos. É neste sentido que o presente estudo ressalta que $O$ Segundo Sexo é também um livro de luta, o qual reivindica a autoafirmação da subjetividade das mulheres por meio da transcendência.

\section{REFERÊNCIAS}

BEAUVOIR, Simone de. A força das coisas; tradução Maria Helena Franco Martins. Rio de Janeiro: Nova Fronteira, 1995.

, Simone de. Moral da ambiguidade (Série Rumos da cultura moderna, volume 34); tradução de Anamaria de Vasconcellos. - Rio de Janeiro: Paz e terra, 1970.

. O segundo sexo: a experiência vivida, volume 2; tradução Sérgio Milliet. - 3. ed. - Rio de Janeiro: Nova Fronteira, 2016b.

O segundo sexo: fatos e mitos; tradução Sérgio Milliet. - 3. ed. - Rio de Janeiro: Nova Fronteira, 2016a.

CYFER, Ingrid. Afinal, o que é uma mulher? Simone de Beauvoir e "a questão do sujeito" na teoria crítica feminista. In: Lua Nova, São Paulo, 94: 41-77, 2015.

FEMENÍAS, María Luisa. A crítica de Judith Butler a Simone de Beauvoir. In: Sapere Aude, v. 3, n. 6, p. 310-339, 2012. Disponível em: http://periodicos.pucminas.br/index. php/SapereAude/article/view/4619. Acesso em: 04 mai. 2020.

Revista Páginas de Filosofia, v. 9, n. 2, p. 183-200, jul.-dez. 2020 
GOTHLIN, Eva. Reading Simone de Beauvoir with Martin Heidegger. In: CARD, Claudia (org.). The Cambridge Companion to Simone de Beauvoir. Cambridge: University Press, 2003, p. 45-65.

KRUKS, Sonia. Simone de Beauvoir: Teaching Sartre About Freedom. In: SIMONS, Margaret A., Feminist interpretations of Simone de Beauvoir. The Pennsylvania State University Press, 1995, p. 79-95.

PARDINA, Teresa L. “Autonomía”, In: AMORÓS, Celia (org.). Diez palabras clave sobre mujer. Navarra: Verbo divino, 1995, pp. 151- 188.

REYNOLDS, Jack. Existencialismo; tradução de Caesar Souza. 2. ed. - Petrópolis, RJ: Vozes, 2014. - (Série Pensamento Moderno).

STF. AÇÃO DIRETA DE INCONSTITUCIONALIDADE POR OMISSÃO 26 DISTRITO FEDERAL. Relator: Ministro Celso de Mello. STF, 2019. Disponível em: https://www.stf.jus.br/ arquivo/cms/noticiaNoticiaStf/anexo/AD026votoMCM.pdf. Acesso em: 06 mai. 2020.

TOMMASI, Wanda. Filósofos y mujeres. La diferencia sexual en la Historia de la Filosofía; tradução Carolina Ballester Messeguer. - Madrid: NARCEA. S.A. DE EDICIONES, 2002.

WEISS, Gail. Challenging Choices: an Ethic of Oppression. In: SIMONS, Margaret A. (org.) The philosophy of Simone de Beauvoir: critical essays. Bloomington: Indiana University Press, 2006, pp. 241-261. 